\title{
Production of High-purity Magnetite Nanoparticles from a Low-grade Iron Ore via Solvent Extraction
}

\author{
Yong Jae Suh*,**, Thi May Do***, Dae Sup Kil*, Hee Dong Jang*** and Kuk Cho***,† \\ *Mineral Resources Research Division, Korea Institute of Geoscience and Mineral Resources, \\ 124 Gwahang-no, Yuseong-gu, Daejeon 305-350, Korea \\ **Nanomaterials Science and Engineering, Korea University of Science and Technology, \\ 217 Gajeong-ro, Yuseong-gu, Daejeon 305-350, Korea \\ ***Department of Environmental Engineering, Pusan National University, \\ 2 Busandaehak-ro 63beon-gil, Geumjeong-gu, Busan 609-735, Korea \\ (Received 12 June 2014; Received in revised form 13 July 2014; accepted 17 July 2014)
}

\begin{abstract}
We produced magnetite nanoparticles (MNPs) and a Mg-rich solution as a nano-adsorbent and a coagulant for water treatment, respectively, using a low-grade iron ore. The ore was leached with aqueous hydrochloric acid and its impurities were removed by solvent extraction of the leachate using tri- $n$-butyl phosphate as an extractant. The content of Si and Mg, which inhibit the formation of MNPs, was reduced from $10.3 \mathrm{wt} \%$ and $15.5 \mathrm{wt} \%$ to $28.1 \mathrm{mg} / \mathrm{L}$ and $<1.4 \mathrm{mg} / \mathrm{L}$, respectively. Consequently, the Fe content increased from $68.6 \mathrm{wt} \%$ to $99.8 \mathrm{wt} \%$. The high-purity $\mathrm{Fe}^{3+}$ solution recovered was used to prepare 5-15-nm MNPs by coprecipitation. The wastewater produced contained a large amount of $\mathrm{Mg}^{2+}$ and can be used to precipitate struvite in sewage treatment. This process helps reduce the cost of both sewage and iron-orewastewater treatments, as well as in the economic production of the nano-adsorbent.
\end{abstract}

Key words: Iron Oxide, Nanomaterial, Environmentally Friendly, Adsorption, Precipitation

\section{Introduction}

Iron-ore tailings have been studied to extract valuable elements while reducing industrial waste, and have been used to produce magnetite powders with submicron to micron particle size [1,2]. Nanoparticles have been produced using iron-ore tailings and pure commercial reagents such as $\mathrm{FeCl}_{2} \cdot 4 \mathrm{H}_{2} \mathrm{O}$ and $\mathrm{FeSO}_{4} \cdot 7 \mathrm{H}_{2} \mathrm{O}[3,4]$. Low-grade tailings have also been purified up to $99.9 \% \mathrm{Fe}$ by solvent extraction $[5,6]$. Solvent extraction is a well-established process of liquid-liquid extraction that relies on the distribution of different components between two immiscible phases.

Inorganic phosphorous in wastewater and sewage is removed by using well-established technologies such as biological uptake, ion exchange, precipitation, and adsorption [7]. Among these technologies, phosphorus adsorption to solid substrates has been widely used and is considered as an effective process. Iron oxyhydroxide adsorbents can achieve high P-removal efficiency because of the strong affinity of the phosphate anions with ferric metal centers [8-11]. However, the conventional micron-sized coagulants suffer from several drawbacks, such as limited P-removal efficiency and difficulties of sludge handling and disposal because of their massive volumes. Nano-

\footnotetext{
${ }^{\dagger}$ To whom correspondence should be addressed.

E-mail: kukcho@pusan.ac.kr

This article is dedicated to Prof. Kyun Young Park on the occasion of his retirement from Kongju National University.

This is an Open-Access article distributed under the terms of the Creative Commons Attribution Non-Commercial License (http://creativecommons.org/licenses/by$\mathrm{nc} / 3.0$ ) which permits unrestricted non-commercial use, distribution, and reproduction in any medium, provided the original work is properly cited.
}

adsorbents can provide more active adsorption sites than the conventional powder, and thus, alleviate the burden of sludge handling and disposal. Because of the favorable adsorption capacity and specific surface area, magnetite nanoparticles (MNPs) are suitable as an effective adsorbent in wastewater treatment. They can also be easily recovered after use because of their excellent magnetic properties [12-16].

The demand for MNPs is very high in water treatment. Therefore, it is necessary to develop a means to reduce the cost of MNPs to make water treatment affordable. Iron-ore tailings or low-grade iron ores, which are much less expensive than high-purity iron ores, can be used as an economic source of $\mathrm{Fe}$ species for producing high-purity MNPs.

In this study, we recovered Fe from a low-grade iron ore by solvent extraction and synthesized MNPs as a nano-adsorbent by coprecipitation. Both solvent extraction [17-19] and coprecipitation [20-22] are practical economic technologies. The impurities were removed from the low-grade iron-ore leachate by solvent extraction using tri- $n$-butyl phosphate (TBP) as an extractant. The high-purity ferric solution thus obtained was used as a starting material for preparing highly crystalline MNPs by coprecipitation, without employing commercial chemicals for iron sources. The Mg-rich wastewater can be used as a precipitating agent to remove phosphate in sewage treatment, which reduces the waste produced by the entire process. Our results suggest that low-grade iron ores or tailings can be exploited to alleviate water contamination, leaving minimal environmental footprint. 


\section{Experimental}

\section{2-1. Materials}

The low-grade iron ore obtained from the Shinyemi mine in Gangwon-do, South Korea, contained approximately $44.30 \% \mathrm{Fe}, 6.35 \%$ $\mathrm{Si}, 9.33 \% \mathrm{Mg}$, and $1.06 \% \mathrm{Al}$. The chemicals used in the crystallization of MNPs were hydrochloric acid ( $\mathrm{HCl}$, Junsei, GR, 35.0-37.0\%), sodium hydroxide ( $\mathrm{NaOH}$, Kanto, Cica reagent, min. 97\%), sodium borohydride $\left(\mathrm{NaBH}_{4}\right.$, Alfa Aesar, $\left.98 \%\right)$, and hydrogen peroxide $\left(\mathrm{H}_{2} \mathrm{O}_{2}\right.$, Junsei, GR, 30\%); all of them were used as received. The organic phase used for solvent extraction was prepared by mixing as received TBP (Junsei, GR), 2-ethyl-1-hexanol (Acros, 99\%), and kerosene (Sigma-Aldrich, RG). 2-Ethyl-1-hexanol and kerosene were, respectively, used as a modifier that enhances phase separation and as a diluent that adjusts viscosity. To test the effect of impurities on ironoxide crystallization, $\mathrm{FeCl}_{2} \cdot 4 \mathrm{H}_{2} \mathrm{O}$ (Sigma-Aldrich, $99 \%$ ), $\mathrm{FeCl}_{3} \cdot 6 \mathrm{H}_{2} \mathrm{O}$ (Sigma-Aldrich, ACS, $97 \%$ ), sodium silicate $\left(\mathrm{Na}_{2} \mathrm{SiO}_{3}\right)$ solution (OCI, $\mathrm{SiO}_{2} 28-30 \%$ ), and $\mathrm{MgCl}_{2} \cdot 6 \mathrm{H}_{2} \mathrm{O}$ (Sigma-Aldrich, ACS, 99.0-102.0\%) were used as received. All the chemical solutions were prepared with ultrahigh pure deionized water.

\section{2-2. Solvent extraction of Fe from iron-ore leachate}

A hydrometallurgical process for producing high-purity ferric ions and subsequently MNPs is depicted in Fig. 1. The solvent extraction process consists of two main steps: extraction and stripping. The extraction step involves selectively separating a metal species of interest from among the species present in an aqueous phase by forming a complex with the organic extractant, and in turn, transferring the complex from the aqueous to the organic phase. Next, the metal species is stripped from the loaded organic phase by a reverse reaction when mixed with a stripping solution. If the selectivity of specific metal species is not very high compared with the other metals, a scrubbing stage should be performed before stripping to remove metal impurities included in the organic extractant.

The purification process was as follows. After crushing of the magnetite iron ore, magnetite powder with particle size less than $149 \mu \mathrm{m}$ was sieved through a No. 100 sieve. To obtain magnetite leachate, $300 \mathrm{~g}$ of magnetite powder and $450 \mathrm{~mL}$ of $35-37 \%(\mathrm{~m} / \mathrm{m}) \mathrm{HCl}$ were placed in a 1-L beaker and stirred at $100{ }^{\circ} \mathrm{C}$ for $2 \mathrm{~h}$. The obtained

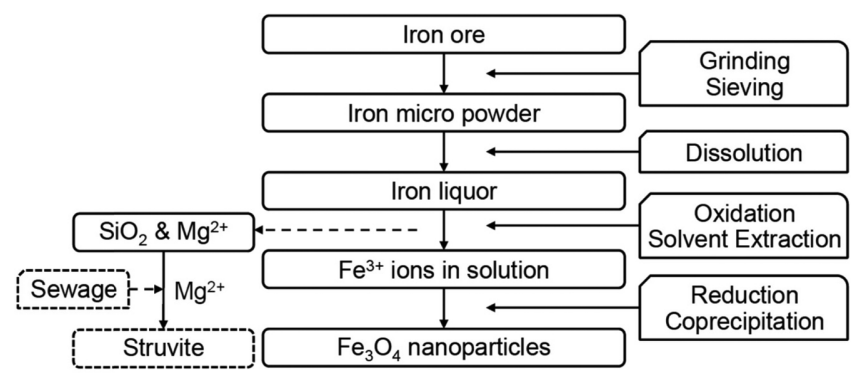

Fig. 1. Flow sheet of the hydrometallurgical process for the synthesis of magnetite $\left(\mathrm{Fe}_{3} \mathrm{O}_{4}\right)$ nanoparticles from a low-grade iron ore by solvent extraction. leachate was centrifuged at an acceleration of $14,752 \mathrm{~g}$ for $10 \mathrm{~min}$ to separate and discharge the residual undissolved powder. Then, $390 \mathrm{~mL}$ of $30 \% \mathrm{H}_{2} \mathrm{O}_{2}$ was added as an oxidant to $300 \mathrm{~mL}$ of the obtained supernatant such that all $\mathrm{Fe}^{2+}$ ions were oxidized to $\mathrm{Fe}^{3+}$ ions, and $810 \mathrm{~mL}$ of distilled water was added to prepare a diluted aqueous solution with the $\mathrm{Fe}^{3+}$-ion concentration of $0.75 \mathrm{M}$. Then, a high-purity iron aqueous solution was obtained by selectively removing the $\mathrm{Fe}^{3+}$ ions from the leachate, in which various metal ions were dissolved, by solvent extraction. To selectively extract the $\mathrm{Fe}^{3+}$ ions from the leachate, $250 \mathrm{~mL}$ of an aqueous solution of leachate and $250 \mathrm{~mL}$ of solvent extractant containing 2.5-M TBP (i.e., a solution containing $170 \mathrm{~mL}$ of TBP, $50 \mathrm{~mL}$ of 2-ethyl-1-hexanol, and $30 \mathrm{~mL}$ of kerosene) were placed in a separating funnel, uniformly mixed with a stirrer for 10 min, and then left for 10 min until an organic phase and an aqueous phase were separated from each other. At this time, silica particles dispersed in a colloidal state in the acidic leachate [23] bonded with the organic phase to form a semitransparent milky emulsion in an organic solution phase and floated on the top of the separating funnel. The aqueous and organic solutions were separated from each other by opening the tap of the separating funnel. The organic solution in which the emulsion was suspended was centrifuged at an acceleration of $14,752 \mathrm{~g}$ for $10 \mathrm{~min}$ to separate and remove the silica particles, obtaining an organic solution containing an iron-extractant complex.

Subsequently, as a stripping process, which is the final step of the solvent extraction, $500 \mathrm{~mL}$ of distilled water was mixed with $250 \mathrm{~mL}$ of the organic phase containing the complex such that the volume ratio of the organic solution to the aqueous solution was 1:2. The mixed solution was placed in a separating funnel, vigorously stirred for $10 \mathrm{~min}$, and then left for $10 \mathrm{~min}$ until phase separation occurred. Then, the tap was opened to separate the aqueous solution, obtaining a highpurity iron aqueous solution containing more than $99 \% \mathrm{Fe}^{3+}$ ions.

\section{2-3. Synthesis of magnetite nanoparticles}

A high-purity ferric solution was used as a starting material to prepare magnetite nanoparticles by coprecipitation. MNPs were coprecipitated when the mixture of ferric and ferrous solution in the ratio of 2:1 was added to a high concentration of hydroxide solution [21]. MNPs are formed by the solid phase reaction according to the following chemical reactions [22]:

$$
\begin{aligned}
& \mathrm{Fe}^{2+}+2 \mathrm{OH}^{-} \rightarrow \mathrm{Fe}(\mathrm{OH})_{2} \\
& \mathrm{Fe}^{3+}+3 \mathrm{OH}^{-} \rightarrow \mathrm{Fe}(\mathrm{OH})_{3} \\
& \mathrm{Fe}(\mathrm{OH})_{3} \rightarrow \alpha-\mathrm{FeOOH}+\mathrm{H}_{2} \mathrm{O} \\
& \mathrm{Fe}(\mathrm{OH})_{2}+2 \alpha-\mathrm{FeOOH} \rightarrow \mathrm{Fe}_{3} \mathrm{O}_{4}+2 \mathrm{H}_{2} \mathrm{O}
\end{aligned}
$$

To synthesize MNPs, a ferrous aqueous solution was prepared by reducing one-third of the high-purity $\mathrm{Fe}^{3+}$ solution. For this purpose, $50 \mathrm{~mL}$ of $0.033 \mathrm{wt} \% \mathrm{NaBH}_{4}$ aqueous solution was added to $167 \mathrm{~mL}$ of $\mathrm{Fe}^{3+}$ aqueous solution corresponding to one-third volume of $500 \mathrm{~mL}$ of $\mathrm{Fe}^{3+}$ aqueous solution and stirred for $10 \mathrm{~min}$. Then, $100 \mathrm{~mL}$ of iron aqueous solution containing $53 \mathrm{~mL}$ of $\mathrm{Fe}^{3+}$ aqueous solution, $35 \mathrm{~mL}$ of $\mathrm{Fe}^{2+}$ aqueous solution, and $12 \mathrm{~mL}$ of distilled water was gradually 
added to $100 \mathrm{~mL}$ of $2.0-\mathrm{M} \mathrm{NaOH}$ alkaline aqueous solution, and the mixed solution was stirred at $40{ }^{\circ} \mathrm{C}$ for 10 min to react with each other, generating MNPs. The prepared nanoparticles were washed three times with distilled water by using a magnet.

The synthetic procedure with commercial reagents is the same as the above except for the preparation of iron salt solution. The salt solution was prepared by dissolving $0.02 \mathrm{~mol}$ of ferric chloride and $0.01 \mathrm{~mol}$ ferrous chloride in $100 \mathrm{~mL}$ deionized water. The mixed iron salt solution was added to $100 \mathrm{~mL}$ of a $1.0-\mathrm{M} \mathrm{NaOH}$ solution to react at $40{ }^{\circ} \mathrm{C}$ for $10 \mathrm{~min}$.

\section{2-4. Characterizations}

The composition of the metal components contained in the MNPs prepared above and the raw iron-ore powder was determined by wet chemical analysis and inductively coupled plasma atomic emission spectrometry (ICP-AES, Jobin-Yvon, JY 38 plus, France). The content of $\mathrm{Fe}$ and $\mathrm{Si}$ was determined by the wet chemical method, while the others by ICP-AES analysis. The metal composition of the aqueous solutions generated during solvent extraction was measured by ICP-AES alone. The size, shape, crystalline structure, surface area, and magnetic properties of nanoparticles were characterized by a transmission electron microscope (TEM, Philips, CM12, Netherlands), an X-ray diffractometer (XRD, Rigaku Denki Co. Ltd., RU-200B, Japan), a surface area analyzer (BET, Micromeritics, TriStar, USA), and a magnetic property measurement system (Quantum Design, MPMS 5T, USA), respectively.

\section{Results and Discussion}

\section{3-1. Solvent extraction of $\mathrm{Fe}$ from iron-ore leachate}

The solvent extraction process for the recovery of Fe using a TBP mixture has been well described elsewhere [6]. TBP is a neutral extractant, making the control of $\mathrm{pH}$ of the aqueous phase before extraction unnecessary; thus, the Fe-TBP complex is easily separated under a neutral or weakly acidic stripping solution. First, the selectivity of the TBP mixture was verified from metal isotherms. The metal isotherms with the mixture containing 2-M TBP, 20\% 2-ethyl-1-hex-

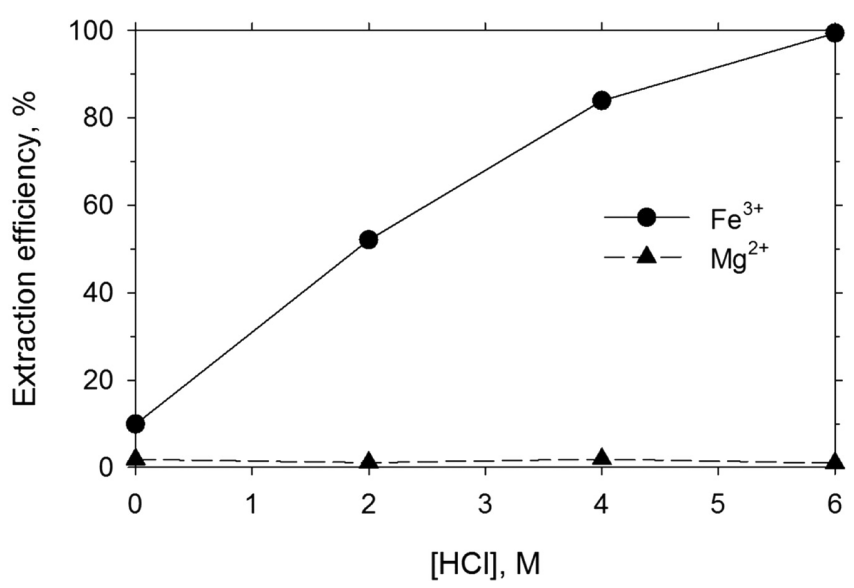

Fig. 2. Isotherms of $\mathrm{Fe}$ and $\mathrm{Mg}$ for solvent extraction using tri- $n$ butyl phosphate as an extractant.

anol, and kerosene were examined for a synthetic solution containing $0.1-\mathrm{M} \mathrm{Fe}^{3+}$ and $0.05-\mathrm{M} \mathrm{Mg}^{2+}$ (Fig. 2). As the concentration of $\mathrm{HCl}$ increased, the extraction efficiency of $\mathrm{Fe}^{3+}$ increased up to $99.4 \%$ at $6 \mathrm{M}$. In contrast, the extraction efficiency of $\mathrm{Mg}^{2+}$ ions remained below $1.9 \%$ for the concentration range 0-6 M. This tendency indicates that $\mathrm{Mg}^{2+}$, the main ionic impurity, cannot be extracted by TBP; therefore, the scrubbing step was not necessary to remove metal ions other than $\mathrm{Fe}^{3+}$ from the loaded organic phase.

To determine the appropriate conditions for $\mathrm{Fe}^{3+}$ extraction from the leachate, the effects of reactant concentrations were investigated $[24,25]$. The effect of $\mathrm{HCl}$ concentration on the extraction of $\mathrm{Fe}(\mathrm{III})$ with a constant iron concentration of $41.6 \mathrm{~g} / \mathrm{L}(0.743 \mathrm{M})$ in the feed solution was investigated in the range of 4-7 M. The extractions were carried out with 2.5-M TBP at a 1:1 phase ratio, increasing Fe(III) extraction from $83.1 \%$ to $97.9 \%$ (Fig. 3a). Excessive $\mathrm{HCl}$ was required in part because of the stoichiometry of the extraction reaction [6]:

$$
\mathrm{Fe}^{3+}+4 \mathrm{Cl}^{-}+\mathrm{H}^{+}+\mathrm{TBP}_{\text {org }} \rightarrow \mathrm{FeCl}_{3} \cdot \mathrm{HCl} \cdot \mathrm{TBP}_{\text {org }}
$$

In addition, the effect of TBP concentration on the extraction of $\mathrm{Fe}$ (III) with an iron concentration of $41.6 \mathrm{~g} / \mathrm{L}$ in a 6-M HCl feed solution was investigated. The concentration of TBP was varied from $0.5 \mathrm{M}$
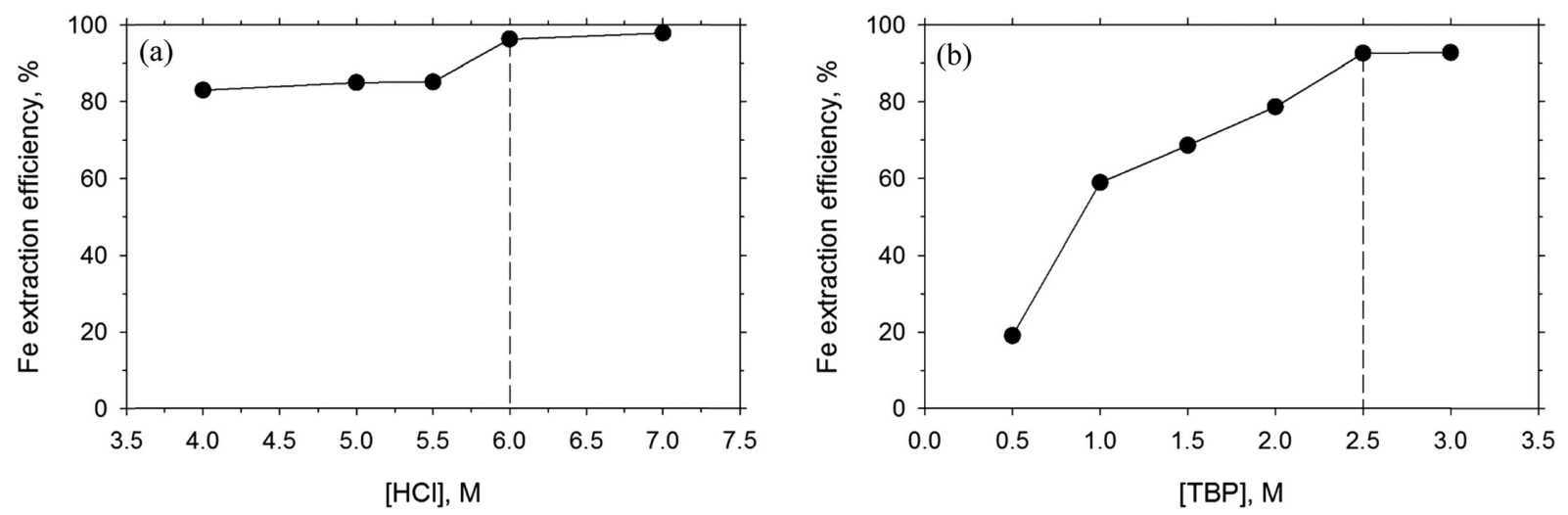

Fig. 3. Effects of reactant concentrations on $\mathrm{Fe}^{3+}$ extraction: (a) Effect of $\mathrm{HCl}$ concentration and (b) Effect of tri- $n$-butyl phosphate (TBP) concentration. 
to $3 \mathrm{M}$ while keeping that of 2-ethyl-1-hexanol constant at $20 \%$ by adding appropriate amounts of kerosene. The extraction efficiency increased from $19.0 \%$ with 0.5 -M TBP up to $92.8 \%$ with 3.0 -M TBP (Fig. 3b). Fig. 3 shows that the extraction efficiencies were nearly saturated when the reactant concentrations were $6.0-\mathrm{M} \mathrm{HCl}$ and $2.5-\mathrm{M}$ TBP. Considering the cost of the chemicals, these values were chosen as the optimum concentrations for extraction.

Furthermore, the extraction efficiency varies with the volume ratio between two phases; it is impossible in a single stage to simultaneously achieve both high recovery and a high extraction efficiency. Thus, multistage extractions are carried out in industries, and a countercurrent cascade arrangement is a common practice [17]. To determine the optimum extraction condition in a countercurrent cascade, the McCabe-Thiele diagram for Fe(III) extraction was plotted with extraction isotherms (Fig. 4a). The aqueous feed solution containing 43.7-g/L Fe and 6-M HCl was mixed and equilibrated with an organic extractant mixture containing 2.5-M TBP and 20\% 2-ethyl-1-hexanol in kerosene for $10 \mathrm{~min}$ each. The Fe concentration of the feed solutions varied slightly between the different sets of experiments. The volume ratio of organic to aqueous phases was varied from 1:5 to 5:1 while keeping the total volume of the two phases constant. After phase disengagement, the aqueous and organic phases were analyzed to determine the Fe concentration. The McCabe-Thiele diagram for extraction (Fig. 4a) indicates that 2-stage extraction with an equal phase volume ratio, $\mathrm{O}: \mathrm{A}=1: 1$, is an appropriate extraction condition to achieve both high recovery and a high efficiency [17].

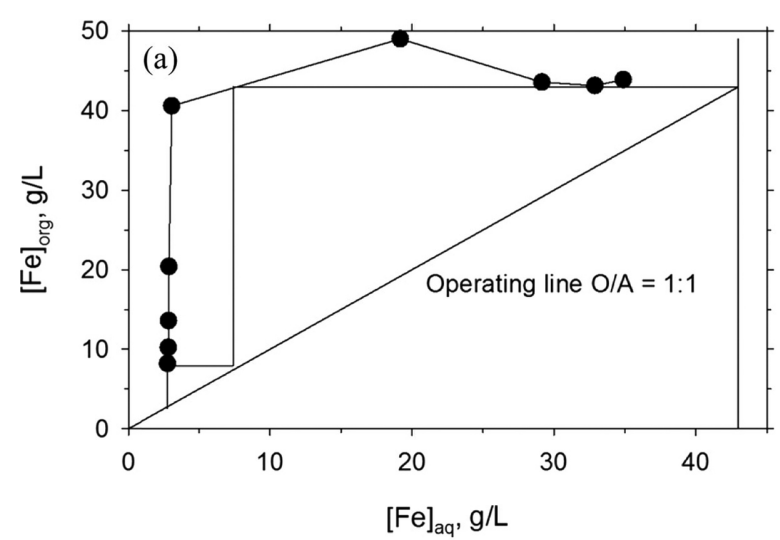

As for stripping process optimization, the stripping isotherm for the Fe-TBP complex phase was investigated. Stripping is the reverse of extraction; therefore, stripping of iron from the organic phase should be carried out under a low-pH condition. As expected, pure distilled water resulted in the highest stripping efficiency of $57.2 \%$ for the phase ratio $\mathrm{O}: \mathrm{A}=1: 1$ with $40.5 \mathrm{~g} / \mathrm{L}$ of Fe-loaded extractant; the efficiency monotonically decreasing with the increase in the $\mathrm{HCl}$ concentration in stripping solutions. Thus, pure distilled water was chosen as the strippant. To determine the required number of stages and the appropriate phase ratio for stripping in a countercurrent cascade arrangement, the stripping isotherm was investigated. The organic phase loaded with $40.5-\mathrm{g} / \mathrm{L} \mathrm{Fe}$ was mixed with distilled water in the O:A range 1:5-5:1 while keeping the total volume of the two phases constant. The concentrations of Fe distributed in the two phases were plotted as a McCabe-Thiele diagram (Fig. 4b), indicating that 2-stage stripping with a phase ratio of $\mathrm{O}: \mathrm{A}=1: 2$ is an appropriate stripping condition [17].

To validate our results for a countercurrent cascade arrangement, extraction and stripping experiments were carried out for the same reagent concentrations as those employed in plotting the McCabeThiele diagrams (Fig. 4) while keeping the phase ratio constant at $\mathrm{O}: \mathrm{A}=1: 1$. The distribution coefficients between the aqueous and organic phases for both extraction and stripping are listed in Table 1 . The volume of the aqueous phase was reduced from $50 \mathrm{~mL}$ to $45 \mathrm{~mL}$ after the extraction (Table 1). This volume change is attributed to the transfer of the $\mathrm{Fe}(\mathrm{III})$ species that forms a complex with $\mathrm{H}^{+}$and $\mathrm{Cl}^{-}$ions and

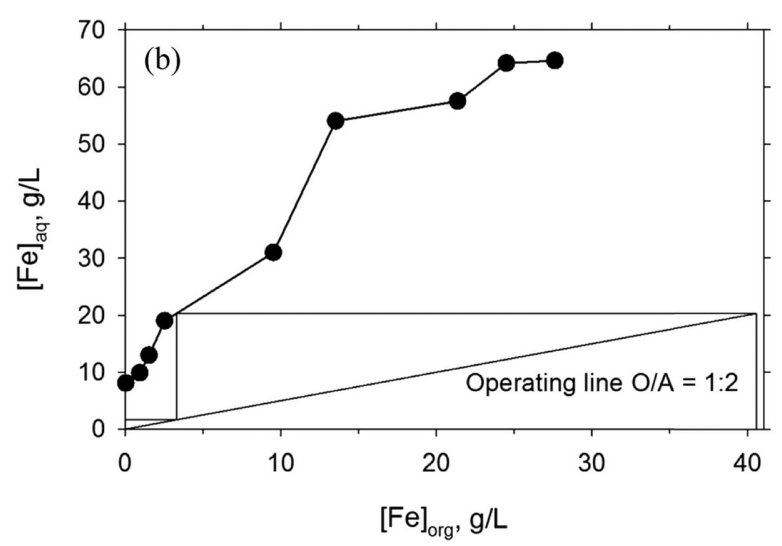

Fig. 4. McCabe-Thiele diagrams for (a) extraction and (b) stripping of $\mathrm{Fe}^{3+}$ ions.

Table 1. Distribution coefficients and separation efficiencies for $\mathrm{Fe}^{3+}$ extraction and stripping

\begin{tabular}{|c|c|c|c|c|c|c|}
\hline \multirow{2}{*}{ Process } & \multicolumn{2}{|c|}{ Aqueous } & \multicolumn{2}{|c|}{ Organic } & \multirow{2}{*}{$\mathrm{D}^{*}$} & \multirow{2}{*}{$\% \mathrm{E}^{\dagger}$} \\
\hline & {$\left[\mathrm{Fe}^{3+}\right](\mathrm{g} / \mathrm{L})$} & Volume (mL) & {$\left[\mathrm{Fe}^{3+}\right](\mathrm{g} / \mathrm{L})$} & Volume $(\mathrm{mL})$ & & \\
\hline Before extraction & 39.78 & 50 & 0.00 & 50 & - & - \\
\hline Extraction & 1.06 & 45 & 35.30 & 55 & 33.5 & 97.1 \\
\hline Stripping, First & 22.78 & 55 & 12.52 & 55 & 1.8 & 64.5 \\
\hline Stripping, Second & 9.47 & 55 & 3.05 & 55 & 10.6 & 91.4 \\
\hline Stripping, Third & 1.40 & 55 & 1.65 & 55 & 20.4 & 95.3 \\
\hline
\end{tabular}

*D represents distribution coefficients, i.e., $\left[\mathrm{Fe}^{3+}\right]_{\text {org }} /\left[\mathrm{Fe}^{3+}\right]_{a q}$ and $\left[\mathrm{Fe}^{3+}\right]_{a q} /\left[\mathrm{Fe}^{3+}\right]_{\text {org }}$ for extraction and stripping, respectively. The subscripts "aq" and "org" represent aqueous and organic phases, respectively.

$\dagger_{\%}$ E represents separation efficiency, i.e., extraction or stripping efficiency for the extraction or stripping step, respectively. 
Table 2. Compositions of metal components in the raw iron ore, in the stripping solution obtained from the stripping stage at the end of the solvent extraction, and in the magnetite nanoparticles prepared from the stripping solution

\begin{tabular}{cccc}
\hline \hline \multirow{2}{*}{ Composition } & \multicolumn{3}{c}{ Concentration of elements } \\
\cline { 2 - 4 } & Ore $(\mathrm{wt} \%)$ & $\begin{array}{c}\text { Stripping solution } \\
(\mathrm{mg} / \mathrm{L})\end{array}$ & $\begin{array}{c}\text { Magnetite nanoparticles } \\
(\mathrm{mg} / \mathrm{L})\end{array}$ \\
\hline $\mathrm{Fe}$ & $68.63^{*}$ & $99.79 \mathrm{wt} \%$ & $99.82 \mathrm{wt} \%^{*}$ \\
$\mathrm{Si}$ & $10.34^{*}$ & 28 & $0.11 \mathrm{wt} \%^{*}$ \\
$\mathrm{Mg}$ & 15.53 & $<1$ & $<12$ \\
$\mathrm{Al}$ & 1.60 & $<21$ & $<105$ \\
$\mathrm{Ca}$ & 1.99 & 150 & 142 \\
$\mathrm{Mn}$ & 1.67 & 25 & 40 \\
$\mathrm{Zn}$ & 0.13 & 190 & 198 \\
$\mathrm{P}$ & 0.03 & $0.16 \mathrm{wt} \%$ & $<173$ \\
$\mathrm{Ti}$ & 0.09 & $<1$ & $<12$ \\
Total & 100.00 & 100.00 & 100.00 \\
\hline
\end{tabular}

*These data were obtained using the wet chemical method, while the others using ICP-AES.

TBP, increasing the volume of the organic phase. The distribution coefficient for extraction, $\left[\mathrm{Fe}^{3+}\right]_{\mathrm{org}} /\left[\mathrm{Fe}^{3+}\right]_{\mathrm{aq}}$, was 33.5 for the first extraction, indicating a very high extraction efficiency of $97.1 \%$. However, the Fe(III) stripping efficiency became as high as $95.3 \%$ after stripping was conducted three times. This relatively low stripping efficiency can be confirmed by examining the corresponding McCabe-Thiele diagram (Fig. 4b). As a result, the phase ratio of O:A $=1: 2$ was suggested for stripping, drawn as the operating line in Fig. 4b.

The compositions of the raw iron-ore powder and recovered solution obtained by the solvent extraction process are compared in Table 2 . In this experiment, the extraction and stripping processes were carried out only once. Among the major metal components, the weight ratio of $\mathrm{Fe}$ increased from $68.6 \%$ in the raw iron ore to $99.8 \%$ in the stripping solution, implying a high selectivity of the TBP mixture. The content of $\mathrm{Si}$ and $\mathrm{Mg}$, which inhibits the formation of MNPs, was $10.3 \mathrm{wt} \%$ and $15.5 \mathrm{wt} \%$ in the raw iron ore, and was significantly reduced to $28.1 \mathrm{mg} / \mathrm{L}$ and $<1.4 \mathrm{mg} / \mathrm{L}$, respectively, in the stripping solution obtained at the end stage of solvent extraction. Certain amounts of colloidal silica and $\mathrm{Mg}^{2+}$ ions prohibited the formation of crystalline magnetite particles, while impurities such as $\mathrm{Al}, \mathrm{Ca}$, and Mn contained in the raw iron ore in several wt $\%$ did not affect the particle formation. This tendency was confirmed using a simulated solution containing the same amount of metal ions as the iron ore in a preliminary study. This is why coprecipitation using the iron leachate prepared by dissolving low-grade iron ore or tailings as a starting material generally does not produce crystalline MNPs. This inhibition was confirmed at the same concentrations of metal components in simulated solutions prepared with commercially available reagents as in the leachate (data not shown).

\section{3-2. Synthesis of magnetite nanoparticles}

The particles prepared in this study were characterized to ensure

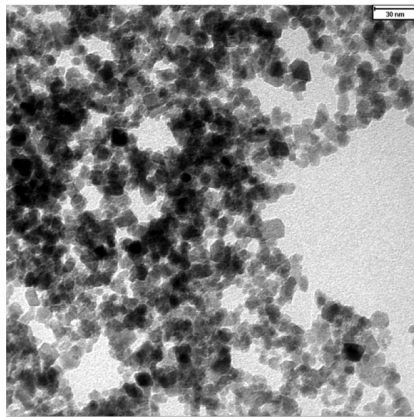

(a)

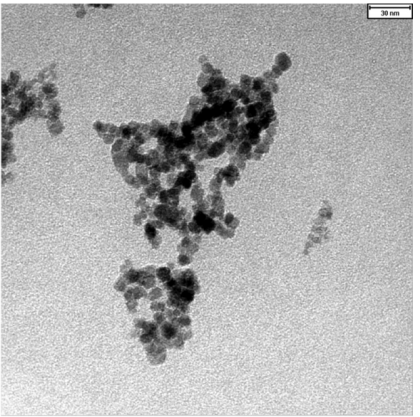

(b)
Fig. 5. Transmission electron microscopy images of magnetite nanoparticles prepared from (a) the stripping solution obtained from solvent extraction and (b) commercial reagents. Scale bar= $30 \mathrm{~nm}$.

the composition, surface area, size, and magnetic properties, which are critical to their application in water treatment. The specific surface area of the particles obtained from the ore was determined at $122.97 \mathrm{~m}^{2} / \mathrm{g}$ by the Brunauer-Emmett-Teller (BET) method. The TEM images of the two powders prepared using the low-grade iron ore by solvent extraction and commercially available reagents are shown in Fig. 5. The average size of the particles $(11.0 \mathrm{~nm})$ produced from the ore leachate (Fig. 5a) is approximately the same as that of the particles $(10.8 \mathrm{~nm})$ prepared with the commercial reagents (Fig. 5b).

To compare the crystalline structures, the XRD patterns of the nanoparticles prepared using the low-grade iron ore by solvent extraction and using commercially available reagents are shown in Fig. 6a. The two nanoparticles exhibited the same pattern as that of magnetite ICDD Card No. 19-0629, thus confirming the crystallization of magnetite. This agreement is considered to occur because the purity of the recovered Fe solution from the ore leachate is as high as that of the commercial reagents (Table 2). The purity of the stripping solution and that of nanoparticles was nearly the same as $99.79 \%$ and $99.82 \%$, respectively.

The magnetic characteristics (Fig. 6b), enabling easy handling of the particle form of industrial materials, showed that the saturated magnetization value of the MNPs prepared using the recovered Fe solution from the leachate was $65.7 \mathrm{emu} / \mathrm{g}$, which is slightly higher than $59.8 \mathrm{emu} / \mathrm{g}$ of the MNPs prepared using the commercially available reagents. Moreover, the MNPs have a coercive force of 0 , and thus, can be effectively recovered and reused in wastewater treatment. This can be understood in the same way as the fact that the nanoparticles could be easily separated from the solvent without using a separate device such as a centrifuge during the preparation of the nanoparticles. For example, in the adsorption stage of water treatment, the nanoparticles in the absence of an external magnetic field should be non-magnetic so that they do not agglomerate with each other, leading to a well-dispersed colloid; while in the recovery stage they should be highly magnetic under a magnetic field for easy retrieval. This superparamagnetic behavior attributed to zero coercivity in part is required for the repetitive usage of the MNPs. 

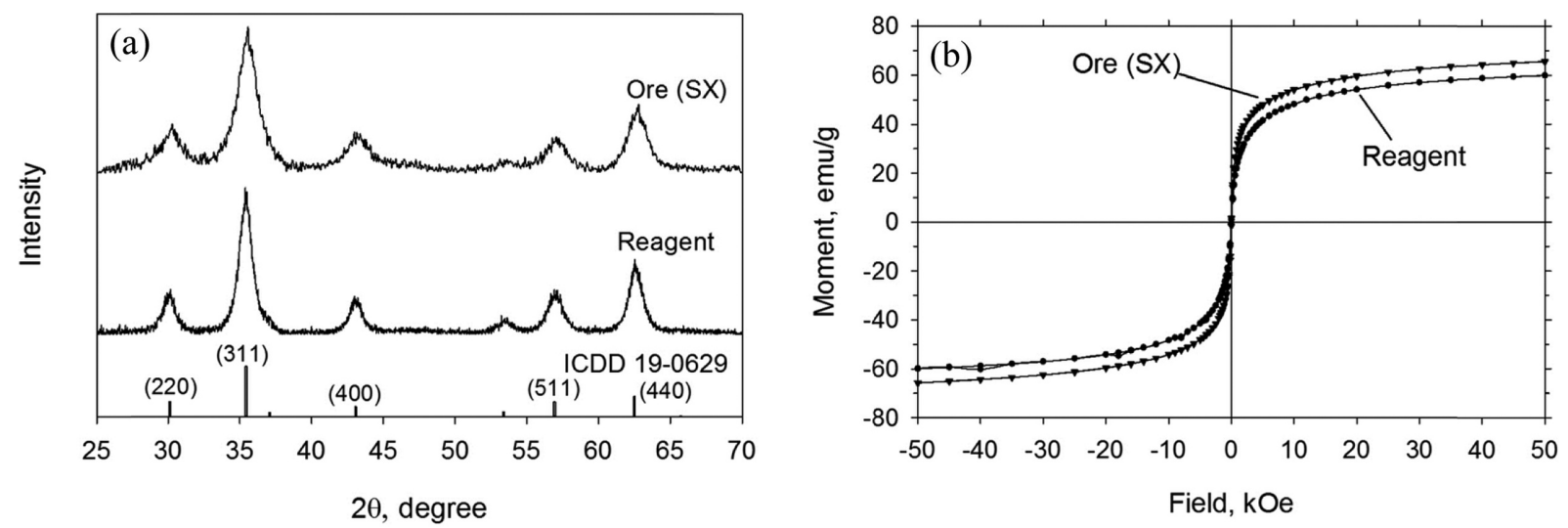

Fig. 6. Crystallinity and magnetization property of magnetite nanoparticles prepared from the stripping solution obtained from solvent extraction and commercial reagents: (a) X-ray diffraction patterns and (b) magnetization curves. SX in "Ore (SX)" stands for solvent extraction.

\section{Conclusions}

We synthesized MNPs with a purity of $99.8 \%$ using a low-grade iron ore as a starting material by a simple hydrometallurgical process. The main impurities of $\mathrm{Si}$ and $\mathrm{Mg}$ were effectively removed by solvent extraction. The solvent extractant used was relatively expensive but can be used dozens of times, thereby significantly reducing the material cost. It is possible to reduce the processing cost and the amount of energy used, thus supplying a high-efficiency MNP adsorbent in large quantities at low cost. Further, the final extraction residue, raffinate, is an aqueous solution containing a large amount of dissolved $\mathrm{Mg}^{2+}$ ions; thus, the residue can be separately used in water purification for removing the phosphorus components present in sewage. The phosphorus is removed in the form of struvite (i.e., ammonium magnesium phosphate hydrate, $\mathrm{NH}_{4} \mathrm{MgPO}_{4} \cdot 6 \mathrm{H}_{2} \mathrm{O}$ ) precipitate $[7,26,27]$, which is a slow-release complex fertilizer. To date, many inexpensive $\mathrm{Mg}$ sources have been sought as the key material to improve the economic feasibility of struvite precipitation [28-32]. Here, we identified another good candidate for $\mathrm{Mg}$ : the iron ore produced at the Shinyemi mine in Gangwon-do, South Korea. Consequently, not only the cost of $\mathrm{Mg}$ but also the cost of iron-ore-wastewater treatment could be reduced. This study may contribute to alleviate water pollution by supplying a magnetic nano-adsorbent and a P coagulant for sewage or wastewater treatment at a reasonable cost.

\section{Acknowledgments}

This research has been performed as part of the project titled "Technology development for the synthesis of nano-materials precursors from mineral resources," supported by the Ministry of Science, ICT and Future Planning of Korea. The authors thank the Geoanalysis Department, Korea Institute of Geoscience and Mineral Resources, and the Division of Materials Science Research, Korea Basic Science Institute, for the characterizations of chemical compositions and magnetic properties, respectively.

\section{References}

1. Giri, S. K., Das, N. N. and Pradhan, G. C., "Magnetite Powder and Kaolinite Derived from Waste Iron ore Tailings for Environmental Applications, Powder Technol., 214(3), 513-518(2011).

2. Sakthivel, R., Vasumathi, N., Sahu, D. and Mishra, B. K., "Synthesis of Magnetite Powder from Iron Ore Tailings,' Powder Technol., 201(2), 187-190(2010).

3. Giri, S. K., Das, N. N. and Pradhan, G. C., "Synthesis and Characterization of Magnetite Nanoparticles Using Waste Iron Ore Tailings for Adsorptive Removal of Dyes from Aqueous Solution,' Colloids Surf., A, 389(1-3), 43-49(2011).

4. Wu, S., Sun, A., Zhai, F., Wang, J., Xu, W., Zhang, Q. and Volinsky, A. A., " $\mathrm{Fe}_{3} \mathrm{O}_{4}$ Magnetic Nanoparticles Synthesis from Tailings by Ultrasonic Chemical Co-precipitation,' Mater. Lett., 65(12), 1882-1884(2011).

5. Mishra, R. K., Rout, P. C., Sarangi, K. and Nathsarma, K. C., "Solvent Extraction of Fe(III) from the Chloride Leach Liquor of Low Grade Iron ore Tailings Using Aliquat 336,' Hydrometallurgy, 108(1-2), 93-99(2011).

6. Mishra, R. K., Rout, P. C., Sarangi, K. and Nathsarma, K. C., “A Comparative Study on Extraction of Fe(III) from Chloride Leach Liquor Using TBP, Cyanex 921 and Cyanex 923', Hydrometallurgy, 104(2), 298-303(2010).

7. Rittmann, B. E., Mayer, B., Westerhoff, P. and Edwards, M., “Capturing the Lost Phosphorus,' Chemosphere, 84(6), 846-853(2011).

8. Ding, M., De Jong, B., Roosendaal, S. and Vredenberg, A., "XPS Studies on the Electronic Structure of Bonding Between Solid and Solutes: Adsorption of Arsenate, Chromate, Phosphate, $\mathrm{Pb}^{2+}$, and $\mathrm{Zn}^{2+}$ Ions on Amorphous Black Ferric Oxyhydroxide,' Geochim. Cosmochim. Acta, 64(7), 1209-1219(2000).

9. Luengo, C., Brigante, M., Antelo, J. and Avena, M., "Kinetics of Phosphate Adsorption on Goethite: Comparing Batch Adsorption and ATR-IR Measurements,' J. Colloid Interface Sci., 300(2), 511-518(2006).

10. Kim, J., Li, W., Philips, B. L. and Grey, C. P., "Phosphate Adsorption on the Iron Oxyhydroxides Goethite $(\alpha-\mathrm{FeOOH})$, Akaganeite $(\beta$ $\mathrm{FeOOH})$, and Lepidocrocite ( $\gamma$-FeOOH): A ${ }^{31} \mathrm{P}$ NMR Study, Energy Environ. Sci., 4(10), 4298-4305(2011).

11. Zach-Maor, A., Semiat, R. and Shemer, H., "Adsorption-desorption 
Mechanism of Phosphate by Immobilized Nano-sized Magnetite Layer: Interface and Bulk Interactions,' J. Colloid Interface Sci., 363(2), 608-614(2011).

12. Hu, J., Lo, I. M. C. and Chen, G., "Removal of Cr(VI) by Magnetite Nanoparticle,' Water Sci. Technol., 50, 139-146(2004).

13. Shipley, H. J., Yean, S., Kan, A. T. and Tomson, M. B., “Adsorption of Arsenic to Magnetite Nanoparticles: Effect of Particle Concentration, pH, Ionic Strength, and Temperature,' Environ. Toxicol. Chem., 28(3), 509-515(2009).

14. Amin, M. M., Khodabakhshi, A., Mozafari, M., Bina, B. and Kheiri, S., "Removal of $\mathrm{Cr}(\mathrm{VI})$ from Simulated Electroplating Wastewater by Magnetite Nanoparticles', Environ. Eng. Manage. J., 9(7), 921927(2010).

15. Chowdhury, S. R. and Yanful, E. K., "Arsenic and Chromium Removal by Mixed Magnetite-maghemite Nanoparticles and the Effect of Phosphate on Removal,' J. Environ. Manage., 91(11), 2238-2247(2010).

16. Do, T. M. and Suh, Y. J., "Removal of Aqueous Cr(VI) Using Magnetite Nanoparticles Synthesized from a Low Grade Iron Ore,' Par. Aerosol Res., 9(4), 221-230(2013).

17. Kislik, V. S., Solvent Extraction: Classical and Novel Approaches, Elsevier, Amsterdam(2012).

18. Nishihama, S., Hirai, T. and Komasawa, I., "Review of Advanced Liquid-liquid Extraction Systems for the Separation of Metal Ions by a Combination of Conversion of the Metal Species with Chemical Reaction,' Ind. Eng. Chem. Res., 40(14), 3085-3091(2001).

19. Flett, D. S., "Solvent Extraction in Hydrometallurgy: The Role of Organophosphorus Extractants,' J. Organomet. Chem., 690(10), 2426-2438(2005).

20. Massart, R., "Preparation of Aqueous Magnetic Liquids in Alkaline and Acidic Media,' IEEE Trans. Magn., 17(2), 1247-1248(1981).

21. Lu, A. H., Salabas, E. L. and Schüth, F., "Magnetic Nanoparticles: Synthesis, Protection, Functionalization, and Application,' Angewandte Chemie - International Edition, 46(8), 1222-1244(2007).

22. Iwasaki, T., Mizutani, N., Watano, S., Yanagida, T. and Kawai,
T., "Size Control of Magnetite Nanoparticles by Organic Solventfree Chemical Coprecipitation at Room Temperature," J. Exp. Nanosci., 5(3), 251-262(2010).

23. Iler, R. K., The Chemistry of Silica, Wiley-Interscience, New York (1979).

24. Lee, J.-K., Jeong, S.-G., Koo, S.-J., Kim, S.-Y. and Ju, C.-S., "Solvent Extraction of Lithium Ion in Aqueous Solution Using TTA and TOPO,' Korean Chem. Eng. Res., 51(1), 53-57(2013).

25. Harvianto, G. R., Jeong, S.-G. and Ju, C.-S., "The Effect of Dominant Ions on Solvent Extraction of Lithium Ion from Aqueous Solution,' Korean J. Chem. Eng., 31(5), 828-833(2014).

26. Le Corre, K. S., Valsami-Jones, E., Hobbs, P. and Parsons, S. A., "Phosphorus Recovery from Wastewater by Struvite Crystallization: A Review,' Crit. Rev. Environ. Sci. Technol., 39(6), 433-477(2009).

27. Parsons, S. A. and Smith, J. A., "Phosphorus Removal and Recovery from Municipal Wastewaters,' Elements, 4(2), 109-112(2008).

28. Shin, H. S. and Lee, S. M., "Removal of Nutrients in Wastewater by Using Magnesium Salts,' Environ. Technol., 19(3), 283-290 (1997).

29. Lee, S. I., Weon, S. Y., Lee, C. W. and Koopman, B., "Removal of Nitrogen and Phosphate from Wastewater by Addition of Bittern,' Chemosphere, 51(4), 265-271(2003).

30. Lahav, O., Telzhensky, M., Zewuhn, A., Gendel, Y., Gerth, J., Calmano, W. and Birnhack, L., "Struvite Recovery from MunicipalWastewater Sludge Centrifuge Supernatant Using Seawater NF Concentrate as a Cheap $\mathrm{Mg}(\mathrm{II})$ Source,' Sep. Purif. Technol., 108, 103-110(2013).

31. Telzhensky, M., Birnhack, L., Lehmann, O., Windler, E. and Lahav, O., "Selective Separation of Seawater $\mathrm{Mg}^{2+}$ Ions for Use in Downstream Water Treatment Processes,' Chem. Eng. J., 175, 136-143 (2011).

32. Quintana, M., Sánchez, E., Colmenarejo, M. F., Barrera, J., García, G. and Borja, R., "Kinetics of Phosphorus Removal and Struvite Formation by the Utilization of by-product of Magnesium Oxide Production,' Chem. Eng. J., 111(1), 45-52(2005). 